\title{
El Peritaje en Psicología Forense
}

\section{Dr. José Luis Oropeza Ortiz*}

Un proceso judicial sin pruebas es como una máquina sin energía, aunque esto sepamos que es la verdad ello no es suficiente, porque se hace necesario demostrarlo, tal vez estemos seguros de que una persona es una víctima y eso debería ser suficiente para que ella fuera protegida por el Estado y pudiera impulsar toda la acción del aparato judicial, pero esto no es así, pues tenemos que evidenciar que hubo un delito, o un ilícito, sustentar que hay una persona afectada en sus bienes jurídicos tutelados, justificar que hay una víctima a través de alguno de los medios probatorios previstos por el estatuto legal, entre los que se encuentra el peritaje, y también el peritaje psicológico forense.

El peritaje debe ser practicado de manera imparcial, aunque debe comprenderse que independientemente de si se dictamina sobre el sujeto activo o pasivo del delito, o ilícito, es decir, independiente de si se es evaluado por un psicólogo forense, desde el estado de posible víctima o agresor y al margen de las creencias o "actitud personales del perito"; es un procedimiento que se realiza para acercarse a la realidad y tener una verdad jurídica y si ello sucede siempre se estará haciendo justicia y favoreciendo a la víctima, es decir, a quien haya padecido el delito o a quien sea inculpando injustamente penal o civilmente.

Estos dos elementos el de establecer la verdad jurídica y hacer justicia son parte de la triada que propone Beristein ${ }^{1}$ para que podamos vivir felices y con dignidad, de manera que el psicólogo forense ejerce un papel fundamental en la construcción social.

Según este planteamiento el peritaje psicológico es un procedimiento matizado con responsabilidad social para auxiliar a las víctimas (porque todo delito causa varias víctimas según Beristain ${ }^{2}$; la norma indica que puede ser realizado desde el ámbito oficial vía ministerio público, como ordena nuestra ley adjetiva y sustantiva mexicana, sin embargo el desconocimiento y la

\footnotetext{
* Docente de la Universidad Nacional Autónoma de México. Correo electrónico: teetetes2@yahoo.com

${ }^{1}$ Beristain, A. (2.001) Algo mejor que la desacralización de la pena kantiana (protagonismo de las víctimas) En Universitas Diciembre de 2.001 (102) 9-16.

2 Beristain, A. (2.001) Algo mejor que la desacralización de la pena kantiana (protagonismo de las víctimas) En Universitas Diciembre de 2.001 (102) 9-16. Ibi,
} 
información de la existencia de la Psicología forense hace que estos casos no sean evaluados correctamente.

Aunque tradicionalmente los profesionales del Derecho recurren a la Instituto oficial encargado, tal vez por la percepción de mayor respaldo institucional o por el desconocimiento de que existen otros peritos tanto o más confiables que los oficiales, o por el pequeño índice de profesionales capacitados en el área no hacen presencia social y permanecen transparentes.

Recurriendo a la fuerza de lo narrativo enunciaré el caso de un joven que tras un trauma craneoencefálico como consecuencia de un accidente de tránsito padeció un trastorno poco evidente y no diagnosticado del control de los impulsos, trastorno que lo llevó a cometer un homicidio y que después de cumplir con las medidas de protección impuestas por ser menor de edad, regresa acudiendo a la justicia para ser evaluado y así justificar que el sistema de seguridad social le brinde el tratamiento que requiere.

Con una evaluación neuropsicología forense se habría podido establecer el diagnóstico a tiempo y ijustificar el tratamiento neurológico! ¡Se habría podido evitar el homicidio! ¿Por qué el joven tiene que suplicar se le brinde un tratamiento? ¿No es apenas un deber de los profesionales de la administración de la justicia aportar todos los conocimientos de la ciencia para evitar dramas como este?

El peritaje psicológico también encuentra justificación cuando se trata de establecer las perturbaciones psicológicas (Art.172, 173, $174 \mathrm{f} \mathrm{I}$, II, III, IV, V, VI, VII $)^{3}$ posteriores a situaciones violentas, por ejemplo el vigilante de un Banco que desencadena una agorafobia (temor a los espacios abiertos) tras presenciar un hurto violento en el que se cometió homicidio y haber padecido el ser amenazado, golpeado y apuntado con un arma de fuego durante varias horas.

La sicopatología es apenas comprensible y obviamente le incapacita para desempeñarse laboralmente razón por la cual el sistema de riesgos profesionales y/o el de seguridad social le debe algunos beneficios protectores y parciales, ya que el perito también debe informar que es una sicopatología que se supera con tratamiento, de manera que no se requiere una indemnización o pensión para toda la vida. Aportar estas informaciones adicionales tiene implicaciones éticas y de justicia por parte del psicólogo forense.

\footnotetext{
${ }^{3}$ Ley General de Salud de la República Mexicana 2000 Ed. Sista S.A. p.p. 40
} 
Otras situaciones victimizantes como las de violencia intrafamiliar ameritan la intervención del peritaje psicológico, por ejemplo cuando el padre de familia ejerce violencia conyugal y maltrato infantil y es denunciado en una oportunidad en la cual no existen evidencias medico-legales del abuso, entonces se puede recurrir a la evaluación psicológica para establecer el perfil de las víctimas, según Echeburúa y Corral ${ }^{4}(1998)$ es muy probable que la mujer presente estrés. postraumático, que tenga altos índices de ansiedad y depresión, además de bajos índices de autoestima y de funcionamiento global ${ }^{5}$.

A través de este peritaje se puede dictaminar con bajísimo margen de error que está padeciendo violencia intrafamiliar y dar paso a las medidas de protección o judiciales elegidas con consentimiento de la víctima y asesoradas por la pericia del psicólogo forense. por la poca difusión del peritaje psicológico como una práctica privada, como sea es una necesidad incrementar desde todas las disciplinas el uso de este medio probatorio.

A continuación deseo relatar anecdóticamente, algunos casos en los cuales resulta evidente y relevante esta intervención profesional, como es la frecuente situación de niños (as) abusados sexualmente que no presentan evidencia física del delito, ya sea porque fueron abusados por medio de caricias o de exhibición del abusador o porque ha pasado demasiado tiempo al momento de denunciar y de presentarse a la práctica del examen sexológico médico-legal, en estos casos es destacable el papel del testimonio del niño y el dictamen pericial del psicólogo de la credibilidad de su relato.

Una de las razones para dudar del testimonio que rinde el (la) niño(a) ante autoridad competente es la creencia popular de que los niños son mentirosos, actúan y hablan de acuerdo con su fantasía, son sugestionables etc., argumentos todos que han sido estudiados científicamente y llegan a la conclusión de que los niños son testigos competentes, que el profesional que reciba su declaración debe capacitarse en específicas técnicas de entrevista, que existen estrategias forenses para evaluarlos y para emitir un dictamen sobre la credibilidad de sus contenidos. Todos estos conocimientos pueden asesorar decisiones judiciales en casos de abuso sexual infantil si se recurre a ellos.

4 Echeburúa, E.; Corral, Paz de (1.998) Manual de violencia familiar. España: Siglo XX

${ }^{5}$ Ley General de Salud de la República Mexicana 2000 Ed. Sista S.A.p.p.40 art 171 
Al caso que me refiero en particular es un tanto grotesco, se trata de un niño que informó haber sido abusado y el defensor del imputado argumentó mitomanía infantil, razón por la cual solicitó un peritaje psicológico.

Durante la evaluación forense el niño informó que el señor X "lo molestaba" y que le había metido "el pene" en la boca y se había "orinado". A su declaración añadió detalles del lugar, de la interacción, reprodujo conversaciones entre ambos, interrupciones inesperadas y otros más aspectos que coinciden con los criterios de realidad establecidos por la técnica de Análisis de Contenido Basado en Criterios Steller v Koenhken ${ }^{6}$, que es una técnica de evaluación psicológica forense que se utiliza con frecuencia en varios países, pero que aún no ha sido validada (estudiada psicométricamente) ni aplicada con población latinoamericana, razón por la cual esta adelantando investigaciones académicas al respecto.

Otra circunstancia que se debería asociar indefectiblemente con el peritaje psicológico es la presencia o presunción de lesiones cerebrales, ya que hay que establecer con precisión el diagnóstico, el pronóstico, la causa y el abordaje medico-legal de estas patologías. Para realizar este diagnóstico Sierra, Jiménez y Bunce $^{7}$ sugieren recurrir siempre al uso de pruebas neuropsicológicas que permitan identificar los déficit con exactitud.

Pero hay que aclarar que no solo cuando se evalúa a las víctimas se les puede auxiliar, también el adecuado dictamen psicológico forense de los transgresores puede ser una manera de proteger a las víctimas o de prevenir situaciones victimizantes con otras personas; lo que sucede cuando se evalúa a un homicida sexual serial del que se presume es psicópata (que es diferente del psicótico, del antisocial, del sociópata y del trastorno antisocial de la personalidad) según los criterios de $\operatorname{Hare}^{10}$ (1999) a través del PCL-R que es otra estrategia de la evaluación psicológica forense.

\footnotetext{
${ }^{6}$ Steller, M.; Koehnken, G. (sf) Análisis de declaraciones basado en criterios. En Raskin, D. (1.994) Métodos psicológicos en la Investigación y pruebas criminales. Bilbao: DDB.

${ }^{7}$ Sierra, J.; Jiménez, E. y Bunce, D. (2.001) Técnicas de evaluación en psicología jurídica y forense. Documento elaborado para el Máster Internacional en Psicología Forense. Universidad de Granada.
} 
Si en la evaluación se confirma el diagnóstico de psicopatía se debe informar que este cuadro diagnóstico no tiene correlación con la inimputabilidad y que la medida recomendada es de máxima seguridad en el tratamiento penitenciario, debido a que los tratamientos psicológicos existentes no muestran eficacia.

Esta intervención pericial solo podría realizarla un psicólogo forense debidamente capacitado y actualizado con el conocimiento mundial y redundaría en el bienestar de las víctimas y de la sociedad en general.

Y para finalizar escribo una nota especificando que el peritaje psicológico se interesa por personas que no necesariamente son víctimas de delitos, pero que en todo caso pueden ser personas desprotegidas que requieren de apoyo estatal como en los procesos de Interdicciones, que son procesos civiles fundamentados con frecuencia en la existencia de un trastorno mental que incapacita a la persona a ejercer sus derechos y sus deberes.

Es decir, la evaluación psicológica forense trasciende el ámbito penal y puede incursionar en el Derecho Civil, el de Familia, el Administrativo, el Disciplinario, el Militar, etc. Y para que se haga una realidad cada vez más frecuente que las víctimas sean apoyadas por este medio probatorio se requiere que los profesionales de la Psicología y del Derecho den a conocer sus aportes. 


\section{REFERENCIAS BIBLIOGRAFICAS}

Beristain, A. (2.001) Algo mejor que la desacralización de la pena kantiana (protagonismo de las víctimas) En Universitas Diciembre de 2.001 (102) 9-16.

Ley General de Salud de la Republica Mexicana 2000 Ed. Sista S.A.

Colombia. Código de Procedimiento Penal. Ley 600 de 2000. Legis Editores S.A.

Echeburúa, E.; Corral, Paz de (1.998) Manual de violencia familiar. España: Siglo XXI

Hare, R. (1.999) La naturaleza de los psicópatas: algunas observaciones para entender la violencia depredadora humana.Trabajo presentado en la Carta reunión internacional sobre biología y sociología de la violencia. Psicópatas y asesinos en serie. Centro Reina Sofía para el Estudio de la violencia. Valencia 15-16 de Noviembre de 1.999.

Sampedro, J.A. (2.001) La memoria de las víctimas: un instrumento en la superación del terrorismo. En Universitas Diciembre de 2.001 (102) 17-27.

Sierra, J.; Jiménez, E. y Bunce, D. (2.001) Técnicas de evaluación en psicología jurídica y forense. Documento elaborado para el Máster Internacional en Psicología Forense. Universidad de Granada.

Steller, M.; Koehnken, G. (sf) Análisis de declaraciones basado en criterios. En Raskin, D. (1.994) Métodos psicológicos en la Investigación y pruebas criminales. Bilbao: DDB. 


\section{(c) (i) \\ Este texto está protegido por una licencia $\underline{\text { Creative Commons }}$ 4.0.}

Usted es libre para Compartir — copiar y redistribuir el material en cualquier medio o formato- y Adaptar el documen- to remezclar, transformar y crear a partir del material - para cualquier propósito, incluso comercialmente, siempre que cumpla la condición de:

Atribución: Usted debe reconocer el crédito de una obra de manera adecuada, proporcionar un enlace a la licencia, e in- dicar si se han realizado cambios. Puede hacerlo en cualquier forma razonable, pero no de forma tal que sugiera que tie- ne el apoyo del licenciante o lo recibe por el uso que hace.

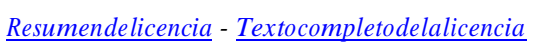

